\title{
Influence of social support to student learning and development
}

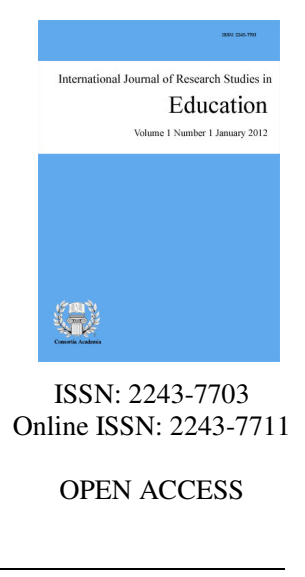

\begin{abstract}
This study aimed to determine which domain in the social support significantly influenced the learning and development of grade six students. The quantitative, non-experimental design utilizing causal effect was used in the study. The respondents were the 179 grade six students from Zone two of New Corella District in the Division of Davao del Norte who were chosen through random sampling. Mean, Pearson-r, and Linear Regression Analysis were the statistical tools used in the study. This study revealed that the social support to grade six students in terms of family, peers and nonrelative adult was very high. Also, student learning and development was very high in terms of physical health and well-being, social connectedness, social and emotional development, school experiences, and use of after school time. The correlation coefficient between variables of this study revealed very high positive significant relationship between social support and student learning and development. Nonrelative adult support revealed as the domain of social support that best predicted the student learning and development of grade six students.
\end{abstract}

Keywords: educational management, social support, student learning and development, Philippines 


\section{Influence of social support to student learning and development}

\section{Introduction}

The learning and development of students involve consideration of physical, emotional, mental, and social aspects. Their attitudes, habits, and competencies are developed from childhood to adolescence and through their lifetime. The younger years have been characterized by a distinct phase in which individuals experience essential socio-emotional developments that contribute to their future growth. Moreover, many studies have found that the younger years are imperative to student learning and wellbeing, so there is a demand for a deeper understanding of what degree of developmental experience can further influence development. Furthermore, studies have shown that brain development among children who live in abusive situations are susceptible to numerous adverse behavioral, educational, and health outcomes due to abuse and neglect (Schonert-Reichl, 2011).

Student learning and development are thought to hold the key to many future results. The early experiences of students establish the groundwork for their outcomes throughout their lifetime. Children's fast rate of brain development and growth rate from birth to age five make this a critical potential and susceptibility period. When the students experience neglect and abusive family, their well-being suffers. It is increasingly clear that the relationships, experiences, and environments a student is exposed to are crucial to their long-term learning and development (Bethell et al., 2017). Social support in the Philippine context may take various forms. It might take the form of just spending quality time around each other, or it can take the shape of aid that is only incidentally linked to the situation at hand. It provides help to someone in managing stressful events or challenges related to their learning and development. Besides, early learner progression has regularly been demonstrated to significantly influence a youngster's long-term outcomes and improving career plans, educational achievement, and even life quality (Reyes et al., 2020).

Commentaries in various Philippine newspapers argue that deviant displays of social and psychological challenges among young people. This can be linked to both social and educational factors. Treating these issues requires a comprehensive approach from a various institution, including family, school, and policy-making organizations (Tomacruz, 2018). Furthermore, students who had a poor perception of the perceived value of support were more prone to have learning and development issues. Students are exposed to various social supports in the Division of Davao del Norte, specifically at Zone two, New Corella District. However, based on their anecdotal records, students who had lesser social support foster poor learning abilities and development in their age. In other words, the relevance of family, school, and peer support for a student's learning and development is critical as a beginning point for developing academic tasks that stimulate not just interpersonal but also holistic growth.

Students who do not have enough support from family members often create school problems such as bullying other students and poor well-being or health development (Blažević, 2016). Thus, this proposal would determine if social support can influence students learning and development in the locality. The researcher has not come across a study similar to the presently undertaken by the researcher at this target locality. There were numerous studies on student learning and development but not to targeted locality. Given, the situations mentioned earlier, this research targeted in exploring students' social support that influence learning and development, which could be alarming in the present society. It is in this context, that the researcher had conducted the study to evaluate the social support acquired by the students. Thus, there is an urgency to conduct the study.

\subsection{Research Objective}

This study is purposely developed to determine the influence of social support on student's learning and 
development. Specifically, it sought to attain the following:

$>\quad$ To describe the level of social support in terms of family support, peers support, and nonrelative adults support.

$>\quad$ To describe the level of student learning and development in terms of physical health and well-being, social connectedness, social and emotional development, school experiences, and use of after school time.

$>$ To determine if there is a relationship between social support to student learning and development.

$>\quad$ To find out if there is a domain in social support that significantly influence student learning and development.

\subsection{Hypothesis}

The following hypotheses were verified at 0.5 significant level:

There is no significant relationship between social support to student learning and development.

There is no domain of social support that significantly influences student learning and development.

\section{Review of Related Literature}

This area of research provides vital information on related studies and literature, which the researcher presented from a thorough review of journals, books, unpublished thesis, periodicals, articles from the internet, and other sources. Several studies were gathered and were keenly reviewed to support to the findings of this research. Reviewed were readings on the independent variable of the study, which is the social support in terms of family assistance, peer assistance, and teacher assistance (Vygotsky,1978; Gordon-Hollingsworth et al., 2015). On the other hand, Schonert-Reichl (2011) identified upbringing, social engagement, well-being are all factors that influence socio-emotional growth and after school time use as indicators for students learning and development.

\subsection{Social Support}

Social ties and social support are generally recognized as essential for psychological health and wellbeing. Several types of social support all represent various aspects of the construct. These include the size and scope of a person's virtual community and the frequency at which they communicate with others. It is believed that belief in social experiences has aided in fulfilling emotional or instrumental needs, including motivation to adopt healthily and reduce risky behaviors; feelings of being understood; assessment of potentially stressful events as less threatening; enhanced sense of control or mastery; increased self-esteem; use of active coping strategies; and the impact of social influence and social comparison (Southwick et al., 2016).

The concepts of "I like myself" and "I believe in myself" and, more specifically, a difference between certain forms of self-concept. As one might expect, self-esteem and personality were related to feeling appreciated by some of the most influential people in someone's existence (Mastoras et al., 2015). On the other hand, it might have a specific link with one's sense of personal or personality, with even more influence from adults on the children's accountability, autonomy, persistence, and personal growth. It also implies that one insufficient source of assistance should be reinforced with aid from a different source.

As an indicator of social support, family support may help children build character in various ways, including fostering a loving connection, modeling the skills they seek to improve, and communicating ideas. Across age groups, emotional demands help and connectivity anticipated global personality. Parenting strategies showed greater specificity in fostering character traits as children grew older. The findings of the study of 
Shubert et al. (2019) show how parenting approaches are linked to the development of general and specific character traits and how these connections alter with age.

Women are more likely than men to seek out and make use of social support. Mothers are likely to be more responsible than fathers for facilitating their children's whereabouts and organizing their lives, resulting in parental warmth and becoming more important in terms a child's development competency. Indeed, previous research has shown that children of parents with good relationships have greater peer relationships and interpersonal skills (Taylor et al., 2015). However, the result of the study of Pinchover and Attar-Schwartz (2018) suggest that children from separated parents and those raised in countries apart from Israel are at a higher risk of having insufficient social networks. The most significant source of encouragement for all of the youth was their mother. Based on the qualities of the teenagers, the sequence of additional sources of help varied. Boys and youth from married-parent families, for instance, ranked paternal aid second, but not by girls and youth from separated families, who evaluated peers as the second most important. It may help in the development of programs that reinforce relations with possible sources of support in their lives.

Previous studies have also found that parenting is related to the quality of family relationships and the low rate of negative parenting methods. Further, beatings lead to hostile and rebellious behaviors among teenagers, and in the long run, it does not develop good habits. Social support has a compelling impact on individualism and collectivist civilizations (Akcinar \& Baydar, 2016). Perceived social support plays a vital role in reducing the incidence of mental illnesses, improving people's depression, life quality, students' mental and emotional health, and their self-esteem and life satisfaction. The effect of psychological disorders was thought to be mitigated by social support. As a result, students who have good emotional, supportive networks such as family and friends have a higher level of life satisfaction. In reality, as their level of happiness and social support rises, they experience less isolation (Kang et al., 2018). Moreover, home transitions may have an impact on family members' social support, affecting marital, family, and interpersonal and inter-relationships. Research has linked marital separation to lower levels of family and adolescent welfare social support assessments. Researchers have also discovered that teenagers from families who have experienced a marital breakup and remarriage appear to have less connectedness and supportive families as a result of reduced parenting practices (usually from the partner with guardianship), increased parent-child tension, as well as others (Amato \& Anthony, 2014).

Consequently, it is also proposed that behavioral and psychological regulation have different effects on adolescent internet addiction. Parents who strictly supervise their children's online behavior pleasantly and sensibly are less likely to have their children become hooked to the internet. On the other hand, parental psychological influence has a detrimental impact on their children's feelings of self-determination, personality, and ability. That can lead to excessive internet use as an unhealthy way of meeting psychological needs (Shek, 2018). Also, parental separation and remarriage can affect social support from other non-family environments. Friendships and good relations with instructors have been demonstrated to be significant stressors for teenagers going through parents' marital breakup transitions. The impact of family and friend evaluations of interpersonal abilities and learning support on mental and emotional health and adolescent growth must always be contextualized. The uniqueness and peculiarities of friendships and the many circumstances that can lead to various activities, regardless of family configuration, can be considered (Leme et al., 2015).

Even though some studies have found that parents and teachers have less impact on teenagers as they progress from elementary to secondary school, they are still important sources of influence. Teachers can express a sense of respect, appreciation, and gratitude for their students. This can be in a quality-based intervention to improve adolescent achievement and engagement in school. Firm and open parental encouragement will foster pro-social conduct in the classroom and enhance academic motivation. Teenagers can use any of these tools for help in this way. On the other hand, these various forms of support certainly don't influence pupils' engagement; similarly, multiple support resources were linked to various dimensions of students' engagement. Furthermore, parents, peers, and teachers had a significant impact on students' achievement and engagement (Abdullah \& Singh, 2019). Further, parents' help with their child's learning process provides several development 
opportunities. Parental engagement in children's learning increases child confidence, behavior, and academic performance across all topics and encourages better conduct and social adjustment. It is also noted that family participation in education encourages children to become productive, accountable parts of society as adults. If parents are interested in educating their children, it is equivalent to saying that the school is proactive in improving or growing among students. As the participation of parents grows, teachers and school administrators often increase the chance to enact quality education reform (Sapungan \& Sapungan, 2014).

Pupils and family networks must help incoming students adjust to a new academic environment by re-establishing a "supportive culture" at either the institution and at home. It's crucial to emphasize that kids establish their informal social support to satisfy their individual needs. Social networks' formation was significantly influenced by sociocultural norms and values, suggesting that students meet peers with similar sociological backgrounds and ethnicities. They were able to openly confront intellectual and social difficulties since they were members of their indigenous groups (Awang et al., 2014). In terms of child welfare, the strengthening of the informal family social support network is a significant step towards improving the safety net for children. Social support is a concept that is recognized as important for mental health in a range of occupations. Children's inclusion in care is said to be influenced by a lack of motivation. A favorable effect on family social support is considered as a coping mechanism for child safety, and social support may be an intermediate outcome for children's social aid homes, with advantages developing over time (Corwin, 2019).

Peer support is psychological or academic assistance for members in a social circle, as well as offering a "listening ear." In teenagers, peer reinforcement leads to more minor misbehavior concerns, better educational outcomes, more life satisfaction, and less emotional stress, like anxiety and depression. Peer reinforcement is crucial in the growth of adolescents in general (Wang et al., 2021). Moreover, peer support is an interactive learning environment, which can be characterized by students assisting classmates in learning topics, or even actual participation by learners with the same wealth and personal status. Although all academics agreed on beginning to follow, this mechanism of students' learning was already described in various ways by different scholars. Regardless of how scholars de ne mentorship, its general concept is to pair a relatively low child with a lifelong career just so the lower-level learner can improve his school achievement without being pressured by an institution, in just this case a "teacher" (Sar1 et al., 2017).

It is recommended that 11year-old children should be more closely related to the influence of their peers rather than to the activities of their parents. However, the influence of parents and peers on children's aggressive behavior will provide parents and children with a more comprehensive picture of the potential impact (Loucaides \& Tsangaridou, 2017). Conversely, it can be challenging to navigate the social world of peers successfully. However, engaging with virtual friends has been beneficial to persons with significant mental illnesses. Personal power and optimism can be used to combat discrimination in online networks. Access to incorrect facts or negative comments by others is also a risk. Researchers conclude that, based on current research, the advantages of peer-to-peer support appear to exceed the hazards (Naslund, 2016).

As a dynamic context, children's growth is believed to be influenced by peer relationships. Approximately $5 \%$ to $10 \%$ of children have persistent peer interaction problems, such as peer rejection and abuse. If peers play a substantial role in developing communication skills, children with poor peer interactions will be more susceptible to later-life mental instability. Because lesser children have fewer opportunities for meaningful adolescent interaction, they are more likely to be bullied. They are deprived of opportunities to learn natural, adaptive social behavior and social cognition (Shin et al., 2016). Moreover, peers impact almost every area of a learner's life, from the mundane to the extreme. It is well known that during adolescence, and peer participation can affect risk-taking behavior. However, the authors claim that the underlying developmental mechanisms are still poorly understood. They argue that empowering teenagers to become more capable decision-makers would be more successful (Ciranka \& Bos, 2019).

Furthermore, during face-to-face and online networks engagements, kids seek benefits through their social 
network of contacts. These methods of assistance have been demonstrated to help people feel less depressed. Students who experienced higher amounts of positive affect are less likely to feel isolated in any way. For college students staying away from parents, peer support may be even more vital than family support (Wright et al., 2013; Bernardon et al., 2011).

To summarize, students who connect with their classmates regularly can better address each other's emotional demands by understanding their emotions. Peer assistance is as effective as licensed therapy and is significantly better than no care (Byrom, 2017). In addition, peers and family members are found to substantially influence pupils' levels of contentment, with family being the essential pillar of help (Basson \& Rothmann, 2018). However, peer support seems to be more important than support from family, according to the argument, because undergraduates have more ties and common interests with their peers than their homes (Bernardon et al., 2011).

Nonrelative adults have no blood relationship or married life and are committed to the welfare of students. Neighbors beside home, educators, local leaders, and religious leaders are all examples. Youth and parenting programs should be expanded to include elements that enable young people and parents to seek resources for non-parenting adults (SNPs) to provide different types of social support that can help young people achieve various achievements. People with normal adolescent awareness (for example, relatives, institutions) should be aware of how they might influence young people in good ways (Gordon, 2011). University students with a lot of social support are more inclined to get a high sense of self-worth, which helps them succeed academically and keeps them emotionally exhausted. Perceived social support is a significant proximal context component that influences student learning and results from expectancies. Individuals' trust that adequate support will be available if required or characterize an atmosphere as helpful or coherent for teaching a given school domain have all been defined as perceived social support. Indeed, a rising amount of proof suggests a clear correlation between human happiness and social life (Rice et al., 2013; Jie Li et al., 2018).

In addition, neighborhood unity describes the sense of belonging and belonging of people in the community and the social support building that generates the social relationships of connection and participation. Neighbors should watch and monitor their children to create a friendly atmosphere, help with stress management, and socialize children in the neighborhood. Neighborhood solidarity may promote increased mutual interaction and social support (Saleem et al., 2016). Accordingly, individual lives impact the daily engagements, social contacts, academic, professional, and leisure opportunities, and wants and aspirations. Their surroundings influence children's growth and wellbeing. According to many studies, attending a low-income community council reduces academic success, and a sense of accomplishment increases the chances of becoming a teenage mother. It may harm on cognitive and emotional health (Owens, 2017).

Similarly, building knowledgeable student groups often require educators to do an excellent job in their respective fields, develop a mentoring plan, and articulate course materials and goals. These teachers promote students' interests through debate, execution, interactive experiences, and group activities. Active education happens whenever teachers attach appropriate resources to the lives of students. The nest teachers set high standards, push students beyond of respective familiar environment, engage students in fun and interactive development, and express compassion about their pupils' training and development (Paolini, 2015).

Although families play a critical part in supporting their children, various loving people can often be helpful throughout puberty, particularly whenever they have problems. When comparing classes, vast variations in person and contextual characteristics are observed, with improved results for adolescents who get help from someone who is not a parent. Such as successful handling mechanisms, greater self-esteem, and identity determination are all examples of coping mechanisms. While the results suggest non-parental people get a favorable impact on various facets of a children's wellbeing, Further studies are needed to understand better why non-parental individuals support youngsters in their early adulthood (Mirković et al., 2021).

Both parents and significant non-parental adults (e.g., neighbors, extended relatives, educators, mentors, and 
trainers) play an active role in fostering positive youth development. It seems to be necessary to recognize the nonparental influences on teenage growth. Furthermore, adolescent involvement and characteristics of critical non-parent adult interactions have been linked to various emotional, racial, and psychological functioning throughout adulthood (Bowers et al., 2015).

For example, older neighbors help to the area's enhanced quality of care for families and children. The contributions of older neighbors mean that they help children build social capital. Older neighbors can support children's well-being by increasing their social value (Jespersen, 2021). Similarly, as young people are becoming more attached to adults who aren't their parents, more information about the pro les of them who have and don't have caring non-parental adults, as well as how they pro t from these relationships, is needed, just like students begin to form adult identities during adolescence. As happens, teachers play a crucial role throughout this process. On the other hand, increased workloads and compliance requirements on educators hurt adolescents' feeling of belonging at school and their behavior, psychological, and academic development (Ibrahim \& Zaatari, 2019).

Further, youngsters with spontaneous mentorship demonstrated higher active parenthood levels than adolescents who lacked genuine advisors, indicating that fostering provided a valuable bene t. Youngsters with the most linked intuitive mentorship ties had positive communication skills and emotional health than those with less or no spontaneous mentoring interactions. The youth engagement partnership's essence has likewise reduced the impact on participating-monitoring parenthood for adolescent development (Hurd et al., 2013). On the other hand, teacher factors affect poor performance or failure in the class. Teachers must exemplify desirable values such as dedication and enthusiasm to improve students' academic performance. Teachers must be able to instill these values in their students and colleagues. They must also have positive feedback that will assist students in their growth (Okoedion, 2019).

\subsection{Students Learning and Development}

Children begin thinking as soon they are born, but children gain knowledge at quite a high rate during their formative days. It lays a vital foundation for long-term success because individuals looking for something and being educated from infancy to eight years old have a powerful meaning for their health, growth, and knowledge. Physical health and wellbeing are a frame of someone's being linked with health and health results and signifies an individual's right to do specified activities or tasks. Students' physical health and wellbeing knowledge, understanding, and skills enable them to be resilient, develop a growth mindset, establish and sustain fulfilling relationships, conduct health promoting judgments about personal education and wellness activities, and build the necessary skills and knowledge to promote their own and others' wellness. Physical health and wellness are essential critical elements in a person's overall development. Positive and motivating physical and social interactions with children allow them to develop positive attitudes (Lynch \& Soukup, 2016).

In a similar vein, physical health is an essential component of learning and student success. Health is similar to the development of children and young adults. Extensive research indicates that frequent physical exercise encourages healthy growth, and it has numerous advantages for physical, mental, intellectual, and interpersonal health, all of which contribute towards knowledge. There has been plenty of experimental evidence involving older kids and adolescents to reinforce the concept that regular exercise provides many of the same health advantages to children and young people (Committee on Physical Activity and Physical Education in the School Environment, 2013). As a result, academic achievement is closely linked to students' mental state and welfare. Physical and psychological wellbeing are deemed to be the most important aspects of wellness by participants. The status of an individual's intellectual, emotional, and cognitive experience is known as psychological health, which affects how they think, interpret, behave, and interact with others. Mental illnesses that go untreated mental problems seem to be more likely to experience a negative impact on academic performance (Huang et al., 2020). 
Furthermore, adolescent lifestyle habits often influence adult wellbeing. However, it may be difficult for young people with mental disorders to participate in optimal or even good health practices. The human body can be compromised and raise the chances of health issues and impaired psychological wellbeing when attitude (depression or stress) providing excellent or able to handle good behaviors like physical exercise, balanced diet, and proper sleep. In particular, for adolescents facing emotional trauma, there seems to be a clear link between limited physical activity and a vegetable diet (Arbour-Nicitopoulos et al., 2012; Herbert \& Cohen, 1993; Nigg \& Amato, 2015). Similarly, it is worth engaging in late childhood sports because it has a bene cial impact on cognitive and emotional functions. However, few studies have focused on the effects of sports on pre-pubertal cognitive function or the cognitive function of different sports disciplines. Such awareness may help develop pre-adolescent training programs to enhance cognitive tasks that are essential to a given sporting discipline (Bidzan-Bluma \& Lipowska, 2018).

Consequently, there is a natural correlation with positive actions between emotion, mental wellbeing, even cognitive and emotional wellness that can last into maturity. These behaviors can have a significant impact on growth, including optimal cognitive, physical, and intellectual development and adverse effects on anxiety, sleep, and opinions. Therefore, changing those habits to boost overall wellbeing and teaching techniques (including modeling), an ultimate component of an effective quality improvement mental healthcare program, could assist young people in learning how to maintain certain good habits (Shevtsova et al., 2017; Preyde et al., 2018). Concerns about learners' wellbeing in university education settings are increasing. As per studies of both the primary and higher education industries, there have been significant correlations among school wellbeing, career excellence, and overall learning goals. Students at universities are becoming more isolated, anxious, and stressed, and these factors were very well drivers of poor academic and personal health outcomes (Zandvliet, 2019). However, it is one of the pressing challenges that teachers face nowadays. Education's primary aim should be to encourage happiness. Mental wellbeing and wellbeing are becoming increasingly critical as modern society becomes more diverse. As a result, we're hearing more and more stories of abuse, violence, bullying, and depression (Student Well-being, 2019).

Notably, research had found that there are connections between social wellbeing and academic performance. According to a major research report, better sleep quality has improved academic performance and daily learning goals. Furthermore, cross-sectional, observational, and several studies found that increasing physical activity and doing solitary durations of exercise improve grades and cognitive performance (Flueckiger, 2017). Social connection refers to the strength of people's social relationships, mutual connections, or shared possibilities. Connectedness could always focus on initiatives intended to improve the protection of young people. Unfortunately, the lack of intercultural communication skills was the most significant barrier to cultural and academic adjustment, according to a survey of 12 international students at Massey University. Cultural compassion and open-mindedness have been linked to academic performance as well as emotional wellbeing. It has the potential to improve educational results (Meng et al., 2018).

Including young people who have severe interpersonal difficulties (for example, cyberbullying, blockage, exclusion), they live in a poor place with a high crime rate, especially with guardians and institutions. They are indeed capable of preventing such various psychological conditions. Increasing the family link and improving parenting (e.g., supervision and explicit communications) may help promote closeness) and result in better youth outcomes. Therefore, ties to compassionate people play an essential part in psychological healing and creating an upbeat personality. When all these children felt "cared about" by somebody, they recounted a cascading of beneficial effects, such as belongingness, inclusion in essential interactions, and confidence in their talents (Foster et al., 2017; Thomas et al., 2012; Noble-Carr et al., 2014). Social life is defined as social trust, positive participation, intellectual integrity, cultural relationships, and communication. Students' learning is affected by these attributes or factors. It benefits people's maturation as well as their financial health. According to numerous scholars, it is thought to influence the growth of learners' critical thinking skills significantly. It instills and retains their excitement and provides emotional support, all of which are essential for building confidence and enhancing the learning process (Sultan, 2020).

76 Consortia Academia Publishing (A partner of Network of Professional Researchers and Educators) 
Social-emotional development is an improvement over time in children's ability to respond and communicate with their social environment. Great opportunities can be found in high-quality classrooms where children have daily interactions with warm and caring teachers. According to a study, children of unhappy mothers have an insecure attachment, low emotional regulation, insufficient cognitive and language processing, unsatisfactory academic performance, increased internalizing and externalizing problems, and less good social skills and social relationships. The emotional climate is one of the most critical aspects of a healthy classroom environment (Yan, 2016). Early psychosocial and social interactions with relatives and relationships with adults and children help shape academic and personal performance and other areas of development. Children get the trust and qualities required to form connections, resolve issues, and deal with problems as they learn social and emotional abilities. Uniquely, academic success is also influenced by emotional development and interpersonal skills. Compared with children with weaker self-control, children with better self-control grow into adults with better health, higher salaries, and fewer financial problems (Halle et al., 2016).

Children's cognitive and emotional development is an essential determinant of school and personal achievement in the present and future. Students learn how to successfully express their feelings, achieve their desires, and manage connections whenever educators react favorably to students' psychological manifestations and assist them in critical thinking and perspective-taking. Teachers who pay attention to and respond to their students' actions and interests help them learn more effectively. Children are competent learners who create their information by involving their surroundings, according to child-centered beliefs. Students learn better when educators are aware of their actions and desires (Lang, 2016). Academic emotions are feelings that are strongly associated with educational experience, classroom management, and success. Pleasure, trust, anger, frustration, and anxiety are all academic emotions. It is possible to differentiate between positive and negative academic emotions. Positive emotions have been shown to increase performance, while negative emotions may have the opposite effect. In addition, positive emotions can help students concentrate and think more clearly, increase academic engagement, and improve academic performance (Dong, 2020).

In addition, children who have improved their personality traits exhibit a greater degree of social maturation, psychological wellbeing, and academic success than those who have not fully grown their emotional skills, according to studies. These young individuals are said to have worse general wellbeing than the first group, including severe depression. They are often more likely to be in violent relationships and to be engaged with addictive substances (Brackett et al., 2015). Schools will offer a rare opportunity to promote youth social-emotional growth. Through interaction with family members, peers, non-relative adults, and course opportunities, some young people can strengthen their mental health and interpersonal skills. It may bene $t$ those who do not have these experiences beyond the school to build social-emotional learning abilities, interpersonal skills, and responsible decision-making (Elias et al., 2015). Consequently, teachers also have a fundamental part in social-emotional learning from children who do not have chances at family or in their societies, who are at risk of educational and behavioral failure. From the perspective of a teacher-student relationship, Dialogue Journal will promote cooperation and trust between teachers and students (Konishi \& Park, 2017).

The relevance of general competence to children in later years results in demonstrating "as children begin to improve social and emotional skills, they acquire the trust and skills required to create relationships through environments, solve problems, and overcome challenges." Social-emotional skills and techniques are built from a sociocultural perspective as children engage in sociocultural activities. Children develop various character traits and knowledge that enable them to recognize and control emotions, achieve goals, respect others' perspectives, feel and show compassion for others, develop and maintain relationships, behave maturely, and deal constructively with individual interactions (Halle \& Darling-Churchill, 2016). Children spend more time in school than almost anywhere, and what happens in school significantly impacts their social and emotional development. Paradoxically, teachers begin to give them less as children grow older and expect more autonomy, respect, and power. Compared with the early elementary school, the characteristics of the elementary school and the late middle school are increased teacher supervision and discipline, while the students' choice and self-management are much less (Schonert-Reichl, 2011). 
Better psychological results are consistently related to more excellent school experiences among children and adolescents. Two cross-sectional analyses using multilevel modeling from the National Longitudinal Study of Adolescent Health showed that students with greater school experiences had lower levels of depression symptoms. According to research, a typical school experience predicts potential depressive symptoms (Yang, 2017). School belonging affects students' psychological, social and academic outcomes. Particular consideration is the effect of school's quality, the learning atmosphere, and relationships between teachers and students. As a result, students with a higher self-identification are more likely to show improved intellectual and psychological performance, increased motivation and enthusiasm towards school, and fewer mental and social challenges (Chiu et al., 2016).

Research shows that student satisfaction is related to their perceptions of justice and equality-related behaviors. Students' satisfaction was found to be predicted by their evaluations of their reasonableness, work schedules, and time demands, as well as instructive management strategies such as explaining grading procedures, providing feedback, and course policies (Chory et al., 2017). Feelings of dedication and attachment affect many students' decisions on whether or not to pursue their studies. Students who struggle to form friendships on their own may feel alone, as if they don't belong, and may drop out. According to research, students who are more academically and socially connected to their schools are more likely to remain in college than those who are less connected (Zinke, 2019).

Being tired indeed makes school more challenging. Students have a harder time demonstrating curiosity and interest. It's as if you're dragging an extra weight around with you. The way students feel at school has a meaningful impact on both their academic success and overall well-being (High school students, 2020). The student's self-concept affects their academic success. Given this, it is the responsibility of teachers, parents, and all stakeholders to consider various factors that may affect positive child self-conception when engaging with or communicating with children. They must also support, track and supervise students to make a certain amount of effort in learning, improving student academic achievement. On the other hand, healthy companionship is related to expanding support and tolerance for school, while the negative relationship is related to leaving school (Crawford, 2013; Garcia-Reid et al., 2015).

Use of After School Time is a non-academic goal and potentially has significant consequences for youth development outcomes. Any out-of-school programs directly or indirectly seek to minimize violent misbehavior and another negative attitude inside and outside of school, reduce drug use, enhance social and emotional performance, and increase school participation and attendance. Factors that lead to post-school programs that reach beyond the educational goals to wellbeing (Durlak et al., 2010). After school events are essential to support student participation because they appear to be both organized and enjoyable, however, most school administrators in the United States are concerned about their students using social media after school time. Adolescence was a period of development long before Snapchat and Instagram, when students took risks, navigated turbulent interpersonal relationships, and tried to accept their selves. On the other hand, social media has become an essential element of such dysfunctional processes (Herold, 2018).

Researchers from the University of Eastern Finland and the University of Jyväskylä investigated children's and mothers' interactions with homework concerning academic performance. Children whose mothers gave them assignment help when they asked for it while also allowing them to work independently persevered longer in tasks and did better in school in the long run. Moms who gave very concrete help, such as sitting down every night to go through every homework assignment even though the child hadn't asked for it, had children who were less consistent over time (Sparks, 2018). Youth who spent more than an hour watching television have been less optimistic and had a more deficient feeling of self-efficacy than with students who spent fewer hours during weekdays. Also, it has been revealed that as gaming increases, social awareness declines. Children engaging in excessive technology usage during classes, primarily playing online video games and television watching, had more adverse effects than children engaged in other practices (Schonert-Reichl, 2011). 
Furthermore, adolescents' health and wellbeing have been seen as both a challenge and an opportunity during after school hours. Researchers have emphasized the benefit of utilizing after school hours as a unique chance for offering skill training and enhancement experiences for teenagers. On the contrary, the increase in youth risk behaviors like abuse, smoking, drinking, and drug use linked to worthless use of after school time. Given the increasing evidence demonstrating the educational importance of after school services for the healthy development of teenagers, they have been viewed as a separate school within the educational system that complements and enhances daily after school activities (Lee et al., 2017).

\subsection{Correlation Between Measures}

The results of several surveys showed that the relationship between social support and student learning and development is an accepted fact. Like, the presence of good social support can lessen the impression of the problems as a threat to one's wellbeing. Also, students are surrounded by powerful role models in their lives, such as their parents and families, characters on children's television, peers in their circle, and teachers at school. If an adult is continually shouting, the child is likely to imitate their actions. It's worth noting that praising a child's actions raises the probability of the behavior continuing exponentially (Gauna, 2017). Furthermore, instructors' social support influences the development of the indicators of students' engagement in school, presented by school involvement, school characteristics, and the utilization of self-regulated tactics. Learners' who are supported by their teachers will tend to meet up their desires to a greater degree, which, thus, decreases distraction and degenerate behavior (Wang \& Holcombe, 2010).

Numerous previous researchers have found a strong link between social support and student well-being. For instance, social support helps youth with problematic conduct to feel less stressed and depressed. Race, housing circumstances, employment position, educational attainment, and home incomes have all been essential factors in fostering student happiness. This emphasizes the importance of making a context-based inquiry into social support and student well-being (Asante, 2012). Based on the findings, students' acknowledged support (from family and teachers) boosted their confidence and improved their self-image. Students who described their parents and teacher as supportive appeared to report higher self-beliefs. Such students, in general, feel confident in mathematics learning, which in turn influences their self-concept. The results affirm the significance of social support in terms of students' academic affective disposition (Bofah \& Ntow, 2017).

Stated on the findings of past studies and the current studies showed that social support and academic achievement have a significant favorable association. Furthermore, the more a person's perception of social support, the greater the extent of adaptation they may make to lives' problems and pressures. Moreover, the findings of the current investigation revealed that there is a link between solitude and academic improvement (Sadoughi \& Hesampour, 2016). All future interactions influence by a sense of stability in social relationships, which begins with one's initial attachment bonds as a child. Due to their decreased social flexibility, they are more likely to be triggered. Their vulnerability and worldview are more pessimistic. They have experienced many social adversities before and may react more negatively to social distancing. On the other hand, it can provide emotional and behavioral tools that can mitigate the negative impact of early adversity in social relationships on loneliness (Ejlskov et al., 2020). Moreover, large family size, illiteracy on the parents, poverty, family pressure, socioeconomic status of the family, family illness and death, and lack of support from family and friends are all factors that can influence a student's learning and development. Students' development success suffers as a result of a lack of support from their families. As a consequence, it may affect on the student's learning and development, leading to emotional issues, a lack of focus in class, and a lack of self-confidence (Okoedion et al., 2019).

Also, drive to adopt healthy and risk-reducing habits; the sense of being acknowledged; perception of possible challenging events as less frightening; increased feeling of control; enhanced self-esteem and influence. On the other hand, the atmosphere of social care will affect the time and degree of expression of these acquired characteristics. Positive social care has also been shown to reduce the genetic risk of depression in children who 
have been abused (Southwick et al., 2016). The aforementioned readings have relevance to the study since they are the base of the formulation of the research problem. The relevant research and literature provided will help researchers develop questionnaires that are used to create links between social support and student learning and development. Furthermore, the relationship between measures takes into account the existence of a wider relationship in order to confirm the theory. In other words, the readings also explain the link between the study's measurements. The researcher considers that there are other elements underlying which provide insights and elucidations to work on hand. Indeed, the literature mentioned above studies lend support to the findings of the study.

\subsection{Theoretical Framework}

This study is anchored on the sociocultural theory that came out of the work of psychologist Lev Vygotsky. He felt that family, peers, and caregivers, in general, were vital in the development of higher cognitive skills. His sociocultural theory shows that social interactions that occur under relevant circumstances have a significant impact on learning (Vygotsky, 1978). In this regard, the child's immediate environment and family members form a crucial social atmosphere for the child's growth and development. Bronfenbrenner's ecological theory (1979) supported the idea of Lev Vygotsky when he highlights the relevance of the surrounding in childhood development. Bronfenbrenner believes that a students' diverse development cannot be understood without considering the child's more significant socio-cultural factors. He established four layers of environmental impacts on children within the ecological theory of development: Microsystems (family, schools, peers, and community), Mesosystems (many Microsystems acting together), Exosystems (the larger environment), and Macrosystems (education, religion, social system). Society's perceptions regarding children and child development influence raising children's practices and probably reflect the unique outcomes recognized in society at the exosystem stage. Schonert-Reichl (2011) identified Middle childhood development is concerned about social-emotional development, school experiences, social connectedness, physical health and wellness, and after school time use.

Further, Erikson's psychosocial development theory (1959) is concerned with the everyday actions in the social environment. It seeks to describe and comprehend how individual overcome ordinary social obligations, particularly personal relationships and views toward society. The middle years of childhood have been characterized as a period of "industry versus inferiority" (Erikson, 1959). At this stage of development, children ought to be involved in various activities that they enjoy and even allow them to develop competencies through the acquisition of new abilities. From a theoretical standpoint, Buunk et al. (1993), Peeters et al. (1995), and Cheuk and Wong (2000) investigated the negative impacts of social support at work. From the viewpoint of equity theory, Buunk et al. (1991) investigated the detrimental effects of social support at work. They discovered that, regardless of the effect of perceived emotional exhaustion, a lack of mutual recognition (receiving too much or too little support) is linked to increased adverse impact. They studied whether receiving social help can lead to sentiments of inadequacy, reliance, and inadequacy.

\subsection{Conceptual Framework}

In Figure 1, the conceptual model of the study reflects the independent variable - social support, and the dependent variable - student learning and development. Communication, asset and information exchange, and passionate and mental assistance are all included in this comprehensive design. The social support indicators are: family support; peer support; and nonrelative adult support. Family support refers to the act of protecting to increase tolerance for unfavorable life events. Peer support refers to showing a meaningful, favorable association with children's positive adaptation and providing them with self-confidence. And nonrelative adult support provides a protective effect through enhancing individuals' learning resources as well as community resources knowledge, understanding, and utilization (Gordon-Hollingsworth et al., 2016).

The indicators of the dependent variable are based on the five dimensions of middle childhood development

80 Consortia Academia Publishing (A partner of Network of Professional Researchers and Educators) 
of Schonert-Reichl (2011) which are: physical health and well-being; social connectedness; social and emotional; school experiences; and use of after school time. Physical health and well-being, when a middle-schooler is healthy, it seems to be more interested in school, feel a connection to their mentors, feel more motivated in participating at school, and become less likely to be bullied or mistreat by others. Social Connectedness is an it is a defensive quality that would have the most link to a child's welfare and development; Social and emotional development is the abilities or skills that allow us to "feel" and optimistically attach; School Experiences may be a significant indicator of their emotional happiness and academic achievement; and Use of after school time can have been a healthy individual and interpersonal growth, feelings of closeness at school, educational achievement, and fewer behavioral issues are all factors that have a significant influence on well-being (Schonert-Reichl, 2011).

Independent Variable

\begin{tabular}{|c|c|}
\hline Social Support & $\begin{array}{l}\text { Students Learning and } \\
\text { Development }\end{array}$ \\
\hline - Family Support & $\begin{array}{l}\text { - Physical Health and } \\
\text { Wellbeing }\end{array}$ \\
\hline - Peers Support & - Social Connectedness \\
\hline \multirow[t]{2}{*}{$\begin{array}{l}\text { - Nonrelative Adult } \\
\text { Support }\end{array}$} & $\begin{array}{l}\text { - Social and Emotional } \\
\text { Development }\end{array}$ \\
\hline & $\begin{array}{l}\text { - Use of After School } \\
\text { Time }\end{array}$ \\
\hline & \\
\hline
\end{tabular}

Figure 1. The Conceptual Framework of the Study

\subsection{Significance of the Study}

This research is important to the researcher because it can help her better understand how to build an educational experience that suits her students. Social support plays an important role in students learning and development. This has been proven to improve psychological state and act as a protective shield against stressful circumstances. Family, friends, and community support have a significant effect on students' behavioral, social, and academic success. The importance of social support on students' well-being was demonstrated by the consistent results from cross-sectional research results (Awang et al., 2014).

The researcher believes that the highlights of this research will present exciting themes and issues that would help future researchers make further investigation implying to the effect of social environment on the students learning and development which results would benefit them. Future researchers may also conduct similar studies in other settings, thus enabling them to refer to this study. Moreover, the results of this study primarily will help determine if there is any relationship between social support and students learning and development which are relevant to the teaching-learning situations. In particular, it will benefit the Department of Education in the formulation of better programs that address the needs on the professional growth of teachers, thus enabling them to identify the best learning styles that address the learning needs of socio-culturally diverse students. This may also lead them to design educational programs that would improve the behavior of students towards learning. best learning styles that address the learning needs of socio-culturally diverse students. This may also lead them to design educational programs that would improve the behavior of students towards learning.

In addition, the results of this study will furnish information about the influence of social support on 
students learning and development. The result will serve as a challenge to the school heads to initiate school-based training to reinforce the student's social support. For the teachers, the results will give them help in improving their skills in delivering their subject matter to the students and improve the students' teaching ability. It will also serve as an awakening call for them to note of the students' social support. Further, the students will be apt to consider the importance of their social support towards their learning and development, which may lead them to continuously develop their competence and improve their learning abilities to become more motivated in their studies.

\section{Method}

Research Design - This study employed a quantitative non-experimental research design using causal effect approach. It is systematic, empirical, and it utilizes various methodological approaches and techniques. This was concerning the relationship between the variables of the study, which were identified and verified through the data from the survey questionnaire. Moreover, the primary purpose of the study was to determine the domains of social support and how they significantly influenced students' learning and development in the schools of New Corella District. The role of correlation research that interests the establishment of ties between at least two or more factors in a similar population or between similar elements in two people was a very significant part of the analysis (Curtis et al., 2016). The recognition of the affiliations and associations that have taken place between social events has become a further impetus for systematic studies in the social sciences as a whole, and this encourages different model variations between other study techniques.

Research Locale - The study results were specific to the settings of the grade six students in zone two of New Corella District in the Division of Davao del Norte. The possibility of the general applicability of the findings was limited to the scope and the sample. Davao del Norte was once recognized just as Davao, currently a province of the Philippines situated in Davao Region in Mindanao. The capital of Davao del Norte is Tagum City, which borders the province of Agusan del Sur towards North, Bukidnon near West, Davao de Oro in the direction of the East, and Davao City toward the South. The location of the respondents is located in Davao del Norte, which consisted of eight municipalities. Furthermore, the place of the respondents and the conduct of the study found in Davao del Norte, particularly in the Municipality of New Corella.

Population and Sample - The research respondents were the grade six students of zone two, New Corella District, Division of Davao del Norte for the school year 2020-2021. The total population is 357, and with Slovin's Formula, the computed sample size was at least utilizing 0.05 level of is significance. The sample size was calculated using Slovin's formula. In terms of precision, Kothari (2004) suggests that the sample findings represent actual state of the population within a given precision range with a confidence level of $95 \%$.

In this study, the researcher described the inclusion criteria of the population (Grade six students) and location (In zone two of New Corella District in the Division of Davao del Norte). Contrary to that, the researcher also described the exclusion criteria of the population (Kinder to Grade five) and the location (Students outside zone two of New Corella District in the Division of Davao del Norte). Based on these inclusion and exclusion criteria, the researcher can make a judgment regarding the impact on the validity of the results of this study. The Respondents can withdraw anytime if they feel threatened with the conduct of the study. Participants have the right to pull out with the research at some stage if they wanted to do so. The respondents should participate based on informed consent.

Research Instrument - This study used two (2) sets of adapted and modified questionnaires to assess the social support and student learning and development of grade six students. Social support has three (3) indicators namely: family support, peer support, and nonrelative adult support. Each indicator has five (5) items. The dependent variable is the student learning and development with physical health and well-being, social connectedness, social and emotional development, school experience, and use of after school time as its five (5) indicators, and each indicator has five (5) items. 
The survey questionnaire had undergone internal and external validation and was submitted to a panel of experts. The questionnaire was content-validated by the external validators with a rating of 4.50 , equivalent to very good. After it was edited, a pilot test was conducted among 50. The result was submitted to the statistician to test its reliability and validation of the terms using Cronbach Alpha. For the independent variable, Cronbach Alpha showed a result of 0.894 with a mean inter-item correlation of 0.358 , which displayed an excellent internal consistency. While the dependent variable gained a Cronbach's Alpha of 0.914 with a mean inter-item correlation of 0.302 that bears an acceptable internal character, meaning, there was a positive correlation between social support and students' learning and development. Thus, all the indicators were related to students' learning and development. After the result of Cronbach Alpha, the researcher proceeded to the actual survey.

Data Gathering Procedure - After the consent of the school head to conduct the study, the researcher personally administered the survey questionnaires to the respondents in the school identified. Unfortunately, because of this pandemic, face-to-face classes are not allowed. Students are not permitted to leave their homes, and only their parents or guardians can get and retrieve their modules. Schedule to meet with teachers and parents strictly following the COVID-19 protocols. Respondents who can access the internet connection for data collection done online, but to those who were unable to do so, the parent or guardian of the respondent submitted the questionnaire to the participant. Furthermore, the administration and retrieval of questionnaires shall be carried out personally by the researcher. After filling out the instruments, these were retrieved in preparation for the next step. Then the collation of data. This includes tallying of responses, after which the result was given to the statistician for the appropriate treatment according to the problems raised in the first chapter. Results were analyzed and interpreted based upon the purpose of the study. The collected data, accompanied by the certificate of appearance from the school head, took five working days.

Voluntary Participation - Students of the chosen educational institution were given the autonomy to participate. They were coerced into participating by implementing penalties, lowering their grades, or any de-merits for not joining. The rights of the respondents were thoroughly considered and adhered to even after this study presented.

Privacy and confidentiality - The researcher had reserved privacy and, with the greatest concealment of the participants and informants' private info that was essential in the research.

Informed Consent Process - The research questionnaire is purposely designed for easy understanding of non-technical respondents. The researcher had formally asked consent to administer the survey from the Schools Division Superintendent and School Heads. With the approval on hand, the respondents were acquainted with the purpose of the study and answered all their questions with satisfaction. Also, the respondents were informed on their rights in participating in the study and signed the informed consent form and assent form.

\section{Results}

It has been noted that the standard deviation ranged from 0.53 to 0.97 , which is less than the typical standard deviation for a 5-point Likert scale. This indicates that the ratings obtained in this study are close to the mean, an indication of smaller variation in the respondents' responses (Wittink \& Bayer, 1994).

\subsection{Level of Social Support}

Presented in Table 1 are the mean scores of social support to students. The data show that the overall mean is 4.45 , with a description equivalent to very high. This implies that the level of social support of students is very high or very much observed. Among the three indicators, family support gets the highest mean score of 4.57, described as very high. Peer support receives a mean of 4.40, also described as very high. And nonrelative adult support has a mean score of 4.37 , still described as very high.

Evidently, in terms of family support, they got the highest mean score of 4.75 or very high with a standard 
deviation of .564 on the questionnaire, which stated, "My family cares about me." Second, they got the mean score of 4.61 or very high with a standard deviation of .672 on the questionnaire, which stated, "My family encourages me." Third, they got the mean score of 4.57 or very high with a standard deviation of .717 on the questionnaire, which stated, "My family shows me affection." Fourth, they got the mean score of 4.49 or very high with a standard deviation of .744 on the questionnaire, which stated, "My family helps me when I need it." Lastly, they got the lowest mean score of 4.40 or still very high with a standard deviation of .811 on the questionnaire, which stated, "My family supports my decisions."

\section{Table 1}

Level of Social Support

\begin{tabular}{lccc}
\hline \multicolumn{1}{c}{ Indicators } & Mean & SD & Descriptive Equivalent \\
\hline Family Support & 4.57 & .494 & Very High \\
Peer Support & 4.40 & .568 & Very High \\
Nonrelative Adult Support & 4.37 & .552 & Very High \\
Overall & 4.45 & .432 & Very High \\
\hline
\end{tabular}

Moreover, in terms of peer support, they got two highest mean score of 4.51 or very high with a standard deviation of .689 and .752 on the questionnaire, which stated, "My family accepts me for who I am.", and "My family gives me good advice." Second, they got the mean score of 4.44 or very high with a standard deviation of .779 on the questionnaire, which stated, "My family helps me feel good about myself." Third, they got the mean score of 4.31 or very high with a standard deviation of .842 on the questionnaire, which stated, "My family shows me affection." Last, they got the lowest mean score of 4.18 or still very high with a standard deviation of .846 on the questionnaire, which stated, "My family cares about me and makes me feel wanted."

Finally, in terms of nonrelative support, they got the highest mean score of 4.47 or very high with a standard deviation of .744 on the questionnaire, which stated, "My family treats me fairly." Secondly, they got the mean score of 4.46 or very high with a standard deviation of .751 on the questionnaire, which stated, "My family accepts me for who I am." Thirdly, they got the mean score of 4.34 or very high with a standard deviation of .773 on the questionnaire, which stated, "My family listens when I want to talk." Then, they got the mean score of 4.29 or very high with a standard deviation of .782 on the questionnaire, which stated, "My family understands me." At last, they got the lowest mean score of 4.27 or still very high with a standard deviation of .834 on the questionnaire, which stated, "My family encourages me."

\subsection{Level of Student Learning and Development}

Table 2 presents the level of student learning and development among grade six students. The data show that the overall mean is 4.42 , with a descriptive equivalent of very high. This indicates that the level of student learning and development among grade six students is very much manifested.

Table 2

Level of Student Learning and Development

\begin{tabular}{lccc}
\hline \multicolumn{1}{c}{ Indicators } & Mean & SD & Descriptive Equivalent \\
\hline Physical Health and Well-being & 4.54 & .442 & Very High \\
School Experience & 4.46 & .530 & Very High \\
Social Connectedness & 4.42 & .506 & Very High \\
Social-Emotional Development & 4.39 & .526 & Very High \\
Time Use & 4.32 & .518 & Very High \\
Overall & 4.42 & .385 & Very High \\
\hline
\end{tabular}

The data show that among the indicators, physical health and well-being gets the highest mean score of 4.54, followed by school experience, which is 4.46 , then social connectedness, which is 4.42 , fourth is social emotional development, which is 4.39 , and time-use gets 4.32 . Meanwhile, in terms of physical health and well-being, they got the highest mean score of 4.61 or very high with a standard deviation of .663 on the 
questionnaire, which stated, "I always eat my breakfast." Secondly, they got two the same mean score of 4.55 or very high with a standard deviation of .679 and .663 on the questionnaire, which stated, "I eat meal with my parents or family members.", and "I eat food like vegetables and fruits." Then, they got the mean score of 4.49 or very high with a standard deviation of .737 on the questionnaire, which stated, "I get a good night's sleep." Lastly, they got the lowest mean score of 4.46 or still very high with a standard deviation of .773 on the questionnaire, which stated, "I go to bed during the weekdays before 9:00 p.m."

Next, in terms of school experience, they got the highest mean score of 4.58 or very high with a standard deviation of .716 on the questionnaire, which stated, "I observe like I belong in this school." Second, they got the mean score of 4.55 or very high with a standard deviation of .735 on the questionnaire, which stated, "I observe teacher and student treat each other with respect." Third, they got the mean score of 4.48 or very high with a standard deviation of .766 on the questionnaire, which stated, "I observe even if the work is hard, I can learn it." Fourth, they got the mean score of 4.39 or very high with a standard deviation of .759 on the questionnaire, which stated, "I observe students help each other, even if they are not friends." Lastly, they got the lowest mean score of 4.27 or still very high with a standard deviation of .812 on the questionnaire, which stated, "I observe people care about each other."

Then, in terms of social connectedness, they got the highest mean score of 4.49 or very high with a standard deviation of .721 on the questionnaire, which stated, "There is a family, a peer or another adult who cares about me." Secondly, they got the mean score of 4.46 or very high with a standard deviation of .736 on the questionnaire, which stated, "There is a family, a peer or another adult who feels when I am in others kids at my age, I feel I belong." Thirdly, they got the mean score of 4.41 or very high with a standard deviation of .747 on the questionnaire, which stated, "There is a family, a peer or another adult who feels that I usually fit in with other kids around me." Fourth, they got the mean score of 4.36 or very high with a standard deviation of .798 on the questionnaire, which stated, "There is a family, a peer or another adult who talks to about my problems." Lastly, they got the lowest mean score of 4.35 or still very high with a standard deviation of .803 on the questionnaire, which stated, "There is a family, a peer or another adult who listens to me when I have something to say."

Further, in terms of social-emotional development, they got the highest mean score of 4.55 or very high with a standard deviation of .779 on the questionnaire, which stated, "I like being the way I am." Second, they got the mean score of 4.47 or very high with a standard deviation of .705 on the questionnaire, which stated, "I feel happy a lot of the time." Third, they got the mean score of 4.41 or very high with a standard deviation of .739 on the questionnaire, which stated, "I start the days thinking I will have a good day." Fourth, they got the mean score of 4.28 or very high with a standard deviation of .766 on the questionnaire, which stated, "I am a person who cares about the feelings of others." Last, they got the lowest mean score of 4.22 or still very high with a standard deviation of .871 on the questionnaire, which stated, "I have a lot to be proud of."

At last, in terms of time use, they got the highest mean score of 4.49 or very high with a standard deviation of .721 on the questionnaire, which stated, "After school I do homework." Second, they got the mean score of 4.39 or very high with a standard deviation of .767 on the questionnaire, which stated, "After school I do sports and /or exercise /or play for fun (for example playing outside, biking or do something else?)." Third, they got the mean score of 4.34 or very high with a standard deviation of .758 on the questionnaire, which stated, "After school I hang out with friends in person." Fourth, they got the mean score of 4.26 or very high with a standard deviation of .856 on the questionnaire, which stated, "After school I watch TV." Last, they got the lowest mean score of 4.10 or still very high with a standard deviation of .883 on the questionnaire, which stated, "After school I visit my family member's home, other places."

\subsection{Significance on the Relationship Between Social Support and Student and Learning and Development}

Presented in Table 3 is the computation using Pearson-r. Nonrelative support gets the highest r-value of 
0.572. It is followed by family support with an R-value of 0.538 , and peer support gets an r-value of 0.480 . Furthermore, the probability level of family support, peer support, and non-relative adult support are equivalent to 0.000 wherein lesser than the significant level of 0.05 . Therefore, the null hypothesis, which stated that there is no significant relationship between social support and the learning and development of grade six students, was not accepted. It further implies that social support has a significant influence to the student learning and development among grade six students. To state more confidently, the research shows a meaningful positive relationship between social support and student learning and development among grade six students. This finding implies that students with more nonrelative adult support are more likely to use power to assist them in learning and developing. Students with a high level of social support are more likely to have high self-esteem, which helps them succeed academically and reduce emotional fatigue. Student retention depends on the ability of nonrelative adults (such as teachers) to communicate their feelings, goals, and grasp support services.

Table 3

Significance on the Relationship Between Social Support and Student Learning and Development

\begin{tabular}{lllll}
\hline \multicolumn{1}{c}{ Social Support } & \multicolumn{1}{c}{ r-value } & $\mathrm{r}^{2}$-value & P-value & Decision \\
\hline Nonrelative Support & $.572 *$ & .327 & .000 & Ho is rejected \\
Family Support & $.538^{*}$ & .289 & .000 & Ho is rejected \\
Peer Support & $.480^{*}$ & .230 & .000 & Ho is rejected \\
\hline Dependent Variable: & Student Learning and Development \\
\hline${ }^{*} p<0.05$ & \multicolumn{4}{l}{}
\end{tabular}

\subsection{Regression Analysis on the Influence of Social Support to Student Learning and Development}

Linear regression analysis was utilized for the validation of which indicators of social support best influence student learning and development among grade six students. Table 4 shows the computed F-ratio of 47.026 and a P-value of 0.000 , which indicates that there is a significant influence of social support on the learning and development of grade six students. The R-value of 0.668 indicates that there is a positive influence of social support on the learning and development of grade six students. The overall $\mathrm{R}^{2}$ is 0.446 , indicating $4.46 \%$ of the students' level of social support is explained by family support, peer support, and non-relative support, and the remaining percentage is accountable for the other indicators not included in the study. Nonrelative adult support gets the highest standardized beta coefficient of 0.363 with the probability value of 0.000 , which is lesser than the 0.05 level of significance it is followed by family support, which has a standardized beta coefficient of 0.293 and a probability value of 0.000 , which is less than the 0.05 level of significance. Peer support has a standardized beta coefficient of 0.169 and a probability value of 0.014 , which is less than the 0.05 level of significance. This means that all the domains of social support are predictors of student learning and development. The study also found that the area of social support has an impact on students' learning and development, with nonrelative adult support having the greatest impact on grade six students' learning and development. In light of discovering that social support for student learning and development is a significant matter, in its place, learners essentially grow and achieve their full potential.

\section{Table 4}

Regression Analysis on the Influence of Social Support to Student Learning and Development

\begin{tabular}{|c|c|c|c|c|c|c|}
\hline \multirow[t]{2}{*}{ Social Support } & \multicolumn{2}{|c|}{$\begin{array}{l}\text { Unstandardized } \\
\text { Coefficients }\end{array}$} & \multirow{2}{*}{$\begin{array}{l}\text { Standardized } \\
\text { Coefficients } \\
\text { Beta }\end{array}$} & \multirow[b]{2}{*}{ t-value } & \multirow[b]{2}{*}{ P-value } & \multirow[b]{2}{*}{ Decision } \\
\hline & $\mathrm{B}$ & Std. Error & & & & \\
\hline (Constant) & 1.777 & .243 & & & & \\
\hline $\begin{array}{l}\text { Nonrelative } \\
\text { Support }\end{array}$ & 0.253 & .065 & $0.363^{*}$ & 5.480 & 0.000 & Ho is rejected \\
\hline Family Support & 0.288 & .080 & $0.293 *$ & 4.354 & 0.000 & Ho is rejected \\
\hline Peer Support & 0.114 & .065 & $0.169 *$ & 2.493 & 0.014 & Ho is rejected \\
\hline \multicolumn{3}{|c|}{ Dependent Variable: } & \multicolumn{4}{|c|}{ Student Learning and Development } \\
\hline \multicolumn{3}{|c|}{$\begin{array}{l}R=0.668 * \\
R^{2}=0.446\end{array}$} & \multicolumn{4}{|c|}{$\begin{array}{l}\text { F-ratio }=47.026 \\
P-\text { value }=0.000\end{array}$} \\
\hline
\end{tabular}




\section{Discussions}

\subsection{Level of Social Support}

The social support to students, as manifested by their ratings in terms of family, peer and nonrelative adult support, was generally very high. This means that the social support of grade six students in terms of family, peer and nonrelative adult support was very much observed. The results indicate that there was a very high level of family support to the learners. This revealed that the learners' family manifested an excellent help when it comes to social support. This result is interrelated to Sapungan and Sapungan (2014) study that learners with supportive families, regardless of ethnic or racial background, socio economic status, or educational level of parents, achieve more. They added that learners also have greater self-esteem, are more self-disciplined, and display higher school expectations and motivation. Evidently, in terms of family support, they got the highest mean score on the questionnaire, which stated, "My family cares about me."

Similarly, social networks of parents have a positive effect on the social competence of children. Research found that parents with solid friendships have higher levels of peer acceptance and social skills (Taylor et al., 2015). In addition, unsurprisingly, having one parent involved is better than having none at all. There was a very high level of peer support to students. This finding is similar to the result of the study by Wang et al. (2021) wherein the peers provide a "listening ear" for those in a peer group. Peer reinforcement leads to less cognitive and behavioral concerns, better academic outcomes, more life satisfaction, and less psychological distress, such as mental health problems, in adolescents. Peer reinforcement is crucial in the growth of adolescents in general.

Also, this result is congruent with the study of Basson and Rothmann (2018) that peers play an important role in fulfilling the requirements for self-reliance, connectedness, and credibility of students. It also fuels a person's desire to grow or perform efficiently. Human beings are thus highly driven, capable of achieving their potential, and capable of finding more significant challenges. In addition, based on the study results of Loucaides and Tsangaridou (2017), spending time with their peers often greater interest in physical activity and greater time playing outdoors relative to those kids who spend time with others.

As observed in the result, the very high level of nonrelative adult support is similar to Gordon's (2011) study. Community members and extended family members' assistance for learners may be more important than that offered by other kinds of support. Similarly, in the study of Saleem et al. (2016), a sense of belonging and belonging among community members, as well as a spurred growth of ties and connections, generates a feeling of connectedness and inclusion. It can create a friendly atmosphere, help with stress management, and socialize children in the neighborhood. Furthermore, parallel to the study of Owens (2017), individual lives have an impact on students' daily habits, social communication, educational, professional, and recreational contingencies, desires, and goals. Students' growth and well-being are influenced by their surroundings. Having grown up in a disadvantaged area lowers educational success and fulfillment, increases the likelihood of teenage pregnancy, and may harm mental and psychological health.

\subsection{Level of Student Learning and Development}

Results of the study revealed that the level of student learning and development of grade six students from zone two of the New Corella District was very high. There was a very high-level rating given by the respondents in terms of physical health and wellbeing, social connectedness, social and emotional development, school experiences, and use of after school time. This means that the student learning and development of grade six students was very much manifested. Specifically, student learning and development in terms of physical health and development. Apparently, the result of the study revealed that the level of student learning and development in terms of physical health and development was very much manifested in their learning and development. With a very high percentage of physical health and development, it indicated that the learning and growth of students was strongly influenced by physical health and development, which also affected the students' learning and 
development.

These findings were the same with the conclusion of the Committee on Physical Activity and Physical Education in the School Environment (2013) that learners' acquisition of knowledge and educational achievement are built on the premise of sound health. Also, personality, socialization, pro-school attitudes, achievement motivation, relatedness to social relationships, team work, harassment, and institutional racism are some of the aspects of psychological wellbeing that generate a good link to physical activity. Moreover, similar results to the study of Preyde et al. (2018), many youths with psychiatric disorders may be at threat of physical health problems because of their lifestyle factors. Collectively, these habits can have a significant impact on growth, including optimal intellectual functioning, physical, and cerebral development, as well as good effects on psychological distress, sleeping, and perspective.

Data also revealed that the level of student learning and development in terms of social connectedness was very high, which means that the student's learning and development were very much manifested. This result is parallel to the study of Schonert-Reichl (2011), which showed that relationships matter. In other words, children who reported positive interactions with their parents, peers, school-related adults, and neighbors had stronger connections than those who didn't disclose such favorable relationships. Therefore, on almost all dimensions of well-being, learners who report interactions and meaningful relationships with essential people in various settings are better than youth who claim a lack of such relations. Also, in the same study by Foster et al. (2017), found that young people have a tendency to form strong and beneficial relationships with adults, and these bonds have been linked to a reduced number of a variety of emotional and psychological issues as well as an increased level of social competence. Children and adolescents who feel linked to individuals and institutions in their communities may be less vulnerable to certain adverse outcomes.

Additionally, student learning and development in terms of Social Emotional Development was very high. This means that the students manifested excellent learning and development. As the result concluded, it parallels to the study of Schonert-Reichl (2011) that the good social skills and emotional health is related to the general wellness of children and provides the basis for a healthy adolescent transition. When transition to middle or secondary school, kids with greater levels of social-emotional well-being more preferable. In relation to social emotional development, physical and mental well-being was to be the most important aspects of wellness by participants. A person's cognitive, emotional, and emotional state, which affects how they think, interpret, behave, and interact with others. Untreated mental diseases are far more likely to harm learning (Huang et al., 2020).

On the other perspective, the study of the level of Student Learning and Development in terms of School Experience was very high, which means that the students were very much manifesting excellent learning and development. This was parallel to the study of Eccles (2013) that Adolescents' knowledge and well-being are generally attributed to school experiences that provided enough and quality resources, a safe setting, and stability of teaching staff.

Lastly, the result of the research revealed that the level of Student Learning and Development in terms of Use of After School Time was very high, which means that the students were very much manifesting excellent learning and development. A very high percentage of use of after-school time indicates that students can do productive activities that contribute to their learning and growth. It was similar to the research of Schonert-Reichl (2011) that use after school time provides of being more advanced and socialization possibilities. Children's participation in after school activities provides different and crucial chances for boosting children's outcomes.

In the same way, harmonious to the study of Durlak et al. (2010) found adolescents who engaged in structured, active, focused, and explicit (SAFE) after school programs experienced significant improvements in their perceptions, emotions, social competence, and academic success. Therefore, use of After School Time is a non-academic goal, and activity potentially has significant consequences for youth development outcomes. 


\subsection{Significance of the Relationship Between Social Support and Student Learning and Development}

This research evolved on the proposition of the Sociocultural theory of Lev Vygotsky (1978). The present study revealed a very high positive significant relationship between social support and learning and development of students. There is a substantial relationship between social support and a range of different outcomes, including family, peer, and nonrelative adult support to learn and develop. Results used on the numerous researches recommended the necessity of development in student consent. Generally, the analysis of existing works recommended the necessity for further studies and experimentally reinforced habits for teachers and learners' improvements that sustain the learning and learning process. However, in these efforts, there has been a lack of specific emphasis on the relationship of social support to students despite that research has related support of society to a wide range of outcomes measures, including the development and learning of students. Likewise, the relationship of social support to students' variables includes family, peer, and nonrelative adult support. Correlation analyses indicated that the learners having more family support have a better chance to endorse and uptight in their learning and development.

\subsection{Regression Analysis on the Influence of Social Support on Student Learning and Development}

The test of significant influence using regression analysis showed that all domains of social support were substantial. This finding was congruent to the proposition of the Sociocultural theory of Lev Vygotsky (1978). The positive relationship of the student's immediate surroundings, which includes family members and others, is indeed a significant social environment for the growth and development of a child. The idea of being supported emphasized the driving force of the students to learn more and develop holistically. This, therefore, made the students more persistent, attentive, and spent more effort, hence leading to increased learning and development. The above findings of the study go with Bronfenbrenner's ecological theory (1979), that nonrelative adult support belongs to a microsystem (family, school, peer group, and neighborhoods) believes that a child's incomparable growth cannot be understood without taking into account his larger social and cultural background. Further, the learners' immediate environment provides learning experiences/alternatives that will address the learning and development of students. The people in the learner's immediate environment have to give importance to social support by committing themselves to providing a variety of experiences that cater to the social support of grade six students. All of these are of particular importance to the students' immediate surroundings, which include family members and others who are accountable for the learning and development of the grade six students.

\section{Conclusion}

Grounded on the results of this research, conclusions are strained in answer to the sub-questions raised in the previous chapter. The respondents from the Province of Davao del Norte, New Corella District, zone two, who are in grade six, have a very high level of performance in terms of social support, which means that they are very highly accorded with family, peer and nonrelative adult social support. On the other hand, learning and development of students is very high, which means that they have excellent learning and developmental growth. Overall, results revealed a significant relationship between social support and learning and development of students. All indicators of the social support used in this study have a very high relationship with the knowledge and development of students. Therefore, it shows that the results among the two variables are statistically very highly noteworthy. This is exposed over the point that more students who participate in purposeful socialization and structured activities at home, school, and society perform better emotionally and mentally than those who do not. Thereupon, authorities, institutions, communities, and families must all work together to provide developmental opportunities for young ones that will help them build their ability, self-esteem, and healthy selves. 


\subsection{Recommendation}

Since the research results show that social support has a significant relationship with student learning and development, it is therefore recommended that governments, organizations, communities, and families continue to support each other in creating formative experiences for children that will develop their competence, confidence, and positive views of themselves. Among the indicators of social support, nonrelative adult support has the lowest mean being identified but still has a very high percentage result. Therefore, it is recommended by students and family members to seek resources for non-parenting adults that can offer the forms of social support that will be the most beneficial and could very highly contribute to their learning and development.

Secondly, peer support is the second highest among the three indicators identified indicators, but still has a very high percentage. Is recommended that teachers may promote peer cooperation or peer teaching in the classroom in which it is a form of cooperative learning environment, such as a learner assisting a fellow student in learning a topic. For the students providing helped it may increase their performance. Consequently, family support has the highest mean being identified. Thus, the students are much engaged and have the most manifestation compare to the other indicator. Therefore, the researcher recommended that family participation should be emphasized and increased in order to grow actively, responsible people in the community. If parents are interested in educating their children, it is equivalent to saying that the school is proactive in bringing about improvement or growth among students. As the participation of parents grows, teachers and school administrators often increase the chance to enact quality education reform.

Moreover, the findings revealed that among the five indicators of student learning and development, the time use had the lowest mean being identified. This indicates that our students are affected by how they spend their time after school as a factor that interrupts their ability to engage and perform in accomplishing a specific result for their learning and development. The researcher, therefore, suggests that student's immediate surroundings, which includes family members and others to value using after school hours as a one-of-a-kind platform to provide youngsters with capacity building and enrichment activities. Any out-of-school programs directly or indirectly seek to minimize violence, misbehavior, and other negative attitudes inside and outside of school, reduce drug use, enhance social and emotional performance, and increase school participation and attendance.

Furthermore, since there is a great association among the indicators of social support as well as learning and development, researcher, recommends that programs be implemented by the Department of Education despite the pandemic and no face-to-face classes, may have any out-of-school activities directly or indirectly seek to minimize violence, misbehavior and other negative attitudes inside and outside of school, reduce drug use, enhance social and emotional performance, and increase school participation and attendance. Also, provide school activities that will involve the parents, siblings, and the students to replace the absence of the teacher. Since, teachers are now very concerned about the learning and development of their students in this time of no face-to-face classes. Therefore, students acknowledged social support boosted their confidence and improved their self-image. The more a student perception of social support, the greater the extent of adaptation they may make to lives' problems and pressures. In general, it may affect on the student's learning and development, feel confident in academic learning, which in turn influences their self-concept.

\section{References}

Abdullah, B., \& Singh, K. (2019). Social support as predictor of student engagement among secondary school students. International Journal of Innovative Technology and Exploring Engineering, 8(7).

Ahmed, W., Minnaert, A., Van Der Werf, G., \& Kuyper, H. (2010). Perceived social support and early adolescents' achievement: The mediational roles of motivational beliefs and emotions. Journal of Youth and Adolescence, 39(1), 36-46. https://doi.org/10.1007/s10964-008-9367-7

Akcinar, B., \& Baydar, N. (2016). Development of externalizing behaviors in the context of family and 
Influence of social support to student learning and development

non-family relationships. Journal of Child and Family Studies, 25(6), 1848-1859. https://doi.org/10.1007/s10826-016-0375-z

Paolini, A. (2015). Enhancing teaching effectiveness and student learning outcomes. The Journal of Effective Teaching, 15, 20-33.

Amato, P. R., \& Anthony, C. J. (2014). Estimating the effects of parental divorce and death with fixed effects models. Journal of Marriage and Family, 76(2), 370-386. https://doi.org/10.1111/jomf.12100

Anderson-Butcher, D., \& Conroy, D. E. (2002). Factorial and criterion validity of scores of a measure of belonging in youth development programs. Educational and Psychological Measurement, 62(5), 857-876. https://doi.org/10.1177/001316402236882

Arbour-Nicitopoulos, K. P., Faulkner, G. E., \& Irving, H. M. (2012). Multiple health-risk behaviour and psychological distress in adolescence. Journal of the Canadian Academy of Child and Adolescent Psychiatry, 21(3), 171-178.

Asante, K. O. (2012). Social support and the psychological wellbeing of people living with HIV/AIDS in Ghana. African Journal of Psychiatry, 15, 340-345. https://doi.org/10.4314/ajpsy.v15i5.42

Awang, M. M. (2012). An exploration of strategies used by Malaysian secondary teachers for promoting positive behaviour: Professionals and Pupils' Perspectives (Unpublished $\mathrm{PhD}$. thesis). United Kingdom: University of Dundee.

Awang, M. M. (2014). Examining gaps between students' expectations and experiences in a Private University. Mediterranean Journal of Social Sciences, 5(8), 396-401.

Awang, M. M., Kutty, F. M., \& Ahmad, A. R. (2014). Perceived social support and well-being: First-year student experience in University. International Education Studies, 7(13). https://doi.org/10.5539/ies.v7n13p261

Basson, M.J., \& Rothmann, S. (2018). Antecedents of basic psychological need satisfaction of pharmacy students: The role of peers, family, lecturers and workload. Research in Social \& Administrative Pharmacy, 14(4), 372-381. https://doi.org/10.1016/j.sapharm.2017.04.015

Bernardon, S., Babb, K.A., Hakim-Larson, J., \& Gragg, M. (2011). Loneliness, attachment, and the perception and use of social support in university students'. Canadian Journal of Behavioural Science, 43(1), 40-51. https://doi.org/10.1037/a0021199

Bethell, C. D., Carle, A., Hudziak, J., Gombojav, N., Powers, K., Wade, R., \& Braveman, P. (2017). Methods to assess adverse childhood experiences of children and families: Toward approaches to promote child well-being in policy and practice. Academic Pediatrics, 17(7). https://doi:10.1016/j.acap.2017.04.161

Bidzan-Bluma, I., \& Lipowska, M. (2018). Physical activity and cognitive functioning of children: A systematic review. International journal of environmental research and public health, 15(4), 800. https://doi.org/10.3390/ijerph15040800

Blažević, I. (2016). Family, peer and school influence on children's social development. World Journal of Education, 6(2). https://doi.org/10.5430/wje.v6n2p42

Bofah, E. A., \& Ntow, F. D. (2017). Perceived social support from parents and teachers' influence on students' mathematics-related self-beliefs. African Journal of Educational Studies in Mathematics and Sciences, 13 .

Boulter, L. T. (2002). Self-concept as a predictor of college freshman academic adjustment. College Student Journal, 36(2), 234-246.

Bowers, E. P., Geldhof, G. J., Johnson, S. K., Hilliard, L. J., Hershberg, R. M., Lerner, J. V., \& Lerner, R. M. (Eds.). (2015). Promoting positive youth development. Advancing responsible adolescent development. Published. https://doi.org/10.1007/978-3-319-17166-1

Brackett, M. A., Elbertson, N. A., \& Rivers, S. E. (2015). Applying theory to the development of approaches to SEL. In J. A. Durlak, C. E. Domitrovich, R. P. Weissberg, \& T. P. Gullotta (Eds.), Handbook of Social and Emotional Learning: Research and Practice (pp. 20-32). New York: The Guildford Press.

Bronfenbrenner, U. (1979). The ecology of human development: Experiments by nature and design. Cambridge, MA: Harvard University Press.

Buunk, B. P., \& Verhoeven, K. (1991). Companionship and support at work: A microanalysis of the stress-reducing features of social interaction. Basic and Applied Social Psychology, 12(3), 243-258. 
https://doi.org/10.1207/s15324834basp1203_1

Buunk, B. P., Doosje, B. J., Jans, L. G. J. M., \& Hopstaken, L. E. M. (1993). Perceived reciprocity, social support, and stress at work: The role of exchange and communal orientation. Journal of Personality and Social Psychology, 65(4), 801-811. https://doi.org/10.1037/0022-3514.65.4.801

Byrom, N. C. (2017). Supporting a friend, housemate or partner with mental health difficulties: The student experience. Early Intervention in Psychiatry, 1-6. https://doi.org/10.1111/eip.12462

C., Rutz, C., \& Willet, G. (2016). Faculty development and student learning: Assessing the connections. Bloomington, IN: Indiana University Press.

Ciranka, S., \& Bos, W. V. (2019). Social influence in adolescent decision-making: A formal framework. Frontiers in Psychology, 10. https://doi.org/10.3389/fpsyg.2019.01915

Cheuk, W. H., Wong, K. S., \& Rosen, S. (2000). Kindergarten principals in Hong Kong. Journal of Educational Administration, 38(3), 272-287. https://doi.org/10.1108/09578230010342330

Chiu, M. M., Chow, B., McBride, C., \& Mol, S. T. (2016). Students' sense of belonging at school in 41 countries: Cross-cultural variability. Journal of Cross-Cultural Psychology, 47(2), 175-196.

Chory, R. M., Horan, S. M., \& Houser, M. L. (2017). Justice in the higher education classroom: Students' perceptions of unfairness and responses to instructors. Innovative Higher Education, 42(4), 321-336. https://doi.org/10.1007/s10755-017-9388-9

Committee on Physical Activity and Physical Education in the School Environment; Food and Nutrition Board; Institute of Medicine; Kohl HW III, Cook HD, editors. Educating the Student Body: Taking Physical Activity and Physical Education to School. Washington (DC): National Academies Press (US); (2013). Physical activity and physical education: Relationship to growth, development, and health. Available from https://www.ncbi.nlm.nih.gov/books/NBK201497/

Cox, B. E., McIntosh, K. L., Terenzini, P. T., Reason, R. D., \& Luovsky Quaye, B. R. (2010). Pedagogical signals of faculty approachability: Factors shaping faculty student interaction outside the classroom. Research in Higher Education, 5, 767-788.

Corwin, T. W., Maher, E. J., Merkel-Holguin, L., Allan, H., Hollinshead, D. M., \& Fluke, J. D. (2019). Increasing social support for child welfare-involved families through family group conferencing. The British Journal of Social Work. https://doi.org/10.1093/bjsw/bcz036

Crawford, W. R. (2013). The relationship of self-concept and academic achievement. Unpublished master's thesis, Glass Bobo States College, Nigeria.

Curtis, E.A., Comiskey, C., \& Dempsey, O. (2016). Importance and use of correlational research. Nurse Researcher, 23(6), 20. https://doi.org/10.7748/nr.2016.e1382

Dong, Y., Wang, H., Zhu, L., Chen, L., \& Yuan, F. (2020). How parental involvement influences adolescents' academic emotions from control-value theory. Journal of Child and Family Studies, 29(2), 282-291. https://doi.org/10.1007/s10826-019-01586-3

Durlak, J. A., Weissberg, R. P., \& Pachan, M. (2010). A meta-analysis of after-school programs that seek to promote personal social skills in children and adolescents. American Journal of Community Psychology, $45,294-309$.

Eccles, J. S. (2013). Schools, academic motivation, and stage-environment fit. Handbook of Adolescent Psychology, 125-153. https://doi.org/10.1002/9780471726746.ch5

Ejlskov, L., Bøggild, H., Kuh, D., \& Stafford, M. (2020). Social relationship adversities throughout the lifecourse and risk of loneliness in later life. Ageing and Society, 40(8), 1718-1734. https://doi.org/10.1017/S0144686X19000345

Elias, M. J., Leverett, L., Duffell, J. C., Humphrey, N., Stepney, C., \& Ferrito, J. (2015). Integrating SEL with related prevention and youth development approaches. In J. A. Durlak, C. E. Domitrovich, R. P. Weissberg, \& T. P. Gullotta (Eds.), Handbook of Social and Emotional Learning: Research and Practice (pp. 33-49). New York: The Guildford Press.

Erikson, E. H. (1959). Identity and the life cycle in psychological issues (monograph). Vol. 1 No. 1 New York: International Universities Press.

Flueckiger, L., Lieb, R., Meyer, A. H., Witthauer, C., \& Mata, J. (2017). Day-to-day variations in health 
Influence of social support to student learning and development

behaviors and daily functioning: two intensive longitudinal studies. Journal of Behavioral Medicine, 40(2), 307-319. https://doi.org/10.1007/s10865-016-9787-x

Fook, C. Y., \& Sidhu, G. K. (2015). Investigating learning challenges faced by students in higher education. Procedia - Social and Behavioral Sciences, 186, 604-612.

https://doi.org/10.1016/j.sbspro.2015.04.001

Foster, C. E., Horwitz, A., Thomas, A., Opperman, K., Gipson, P., Burnside, A., Stone, D. M., \& King, C. A. (2017). Connectedness to family, school, peers, and community in socially vulnerable adolescents. Children and youth services review, 81, 321-331. https://doi.org/10.1016/j.childyouth.2017.08.011

Garcia-Reid, P., Peterson, C. H., \& Reid, R. J. (2015). Parent and teacher support among Latino immigrant youth: Effects on school engagement and school trouble avoidance. Education and Urban Society, 47(3), 328-343.

Gauna, R. (2017). The peer leaders uniting students (PLUS) program: The impact on school climate, student engagement, and student mentoring (Order No. 10604062). Available from ProQuest Central. (1937447104). https://www.proquest.com/dissertations-theses/peer-leaders-uniting-students-plus-program-impact/docv iew/1937447104/se-2?accountid=31259

Gordon, A. T. (2011). Assessing social support in children: development and initial validation of the social support questionnaire for children. LSU Doctoral Dissertations. 3529. https://digitalcommons.1su.edu/gradschool_dissertations/3529

Gordon-Hollingsworth, A. T., Thompson, J. E., Geary, M. A., Schexnaildre, M. A., Lai, B. S., \& Kelley, M. L. (2016). Social support questionnaire for children. Measurement and evaluation in counseling and development, 49(2), 122-144. https://doi.org/10.1177/0748175615596780

Halle, T. G., \& Darling-Churchill, K. E. (2016). Review of measures of social and emotional development. Journal of Applied Developmental Psychology, 45, 8-18. https://doi.10.1016/j.appdev.2016.02.003

Herbert, T. B., \& Cohen, S. (1993). Depression and immunity: A meta-analytic review. Psychological Bulletin, 113(3), 472-486. https://doi.org/10.1037/0033-2909.113.3.472

Herold, B. (2018). On social media, principals struggle to keep pace: Students' online behavior outside of school is a big worry, survey shows. But most principals don't feel prepared to tackle the challenge. Education Week, 37(27).

Herrmann, K., Bager-Elsborg, A., \& McCune, V. (2017). Investigating the relationships between approaches to learning, learner identities and academic achievement in higher education. Higher Education, 74, 385-400.

High school students report negative feelings for school: Study (2020). Asian News International. ProQuest. https://www.proquest.com/newspapers/high-school-students-report-negative-feelings/docview/2348805 033/se-2?accountid=31259

Huang, L., Kern, M. L., \& Oades, L. G. (2020). Strengthening university student wellbeing: Language and perceptions of chinese international students. International Journal of Environmental Research and Public Health, 17(15), 5538. https://doi.org/10.3390/ijerph17155538

Hurd, N. M., Varner, F. A., \& Rowley, S. J. (2013). Involved-vigilant parenting and socio-emotional well-being among black youth: The moderating influence of natural mentoring relationships. Journal of Youth and Adolescence, 42, 1583-1595.

Ibrahim, A., \& El Zaatari, W. (2019). The teacher-student relationship and adolescents' sense of school belonging. International Journal of Adolescence and Youth, 25(1), 382-395. https://doi.org/10.1080/02673843.2019.1660998

Jespersen, B. V., Korbin, J. E., \& Spilsbury, J. C. (2021). Older neighbors and the neighborhood context of child well - being: Pathways to Enhancing Social Capital for Children. American Journal of Community Psychology. https://doi.org/10.1002/ajcp.12520

Li, J., Han, X., Wang, W., Sun, G., \& Cheng, Z. (2018). How social support influences university students' 
academic achievement and emotional exhaustion: The mediating role of self-esteem. Learning and Individual Differences, 61, 120-126. https://doi.org/10.1016/j.lindif.2017.11.016

Kang, H. W., Park, M., \& Wallace-Hernandez, J. P. (2018). The impact of perceived social support, loneliness, and physical activity on quality of life in South Korean older adults. Journal of Sport and Health Science, 7(2), 237-244. https://doi.org/10.1016/j.jshs.2016.05.003

Komarraju, M., Musulkin, S., \& Bhattacharya, G. (2010). Role of student-faculty interactions in developing college students' academic self-concept, motivation, and achievement. Journal of College Student Development, 51, 333-342.

Konishi, C., \& Park, S. (2017). Promoting children's healthy social-emotional growth: Dialogue Journal. Journal of Education and Learning, 6(2), 246. https://doi.org/10.5539/jel.v6n2p246

Kothari, C. R. (2004). Research Methodology: Methods and techniques (2nd revised edition). New Delhi: New Age International (P) Limited, Publishers.

Landman-Peeters, K. M.C., Hartman, C. A., van der Pompe, G., den Boer, J. A., Minderaa, R. B., \& Ormel, J. (2005). Gender differences in the relation between social support, problems in parent-offspring communication, and depression and anxiety. Social Science \& Medicine, 60, 2549-2559. https://doi:10.1016/j.socscimed.2004.10.024

Lang, S. N., Mouzourou, C., Jeon, L., Buettner, C. K., \& Hur, E. (2016). Preschool teachers' professional training, observational feedback, child-centered beliefs and motivation: Direct and indirect associations with social and emotional responsiveness. Child \& Youth Care Forum, 46(1), 69-90. https://doi.org/10.1007/s10566-016-9369-7

Lee, O., Park, M., Jang, K., \& Park, Y. (2017). Life lessons after classes: Investigating the influence of an afterschool sport program on adolescents' life skills development. International Journal of Qualitative Studies on Health and Well-being, 12(1), 1307060. https://doi.org/10.1080/17482631.2017.1307060

Leme, V. B. R., Del Prette, Z. A. P., \& Coimbra, S. (2015). Social skills, social support and well-being in adolescents of different family configurations. Paidéia (Ribeirão Preto), 25(60), 9-17. https://doi.org/10.1590/1982-43272560201503

Liu, W., Mei, J., Tian, L., \& Huebner, E. S. (2015). Age and gender differences in the relation between school-related social support and subjective well-being in school among students. Social Indicators Research, 125(3), 1065-1083. https://doi.org/10.1007/s11205-015-0873-1

Longobardi, C., Prino, L. E., Marengo, D., \& Settanni, M. (2016). Student-teacher relationships as a protective factor for school adjustment during the transition from middle to high school. Frontiers in Psychology, 7. https://doi.org/10.3389/fpsyg.2016.01988

Loucaides, C. A., \& Tsangaridou, N. (2017). Associations between parental and friend social support and children's physical activity and time spent outside playing. International Journal of Pediatrics, 1-11. https://doi.org/10.1155/2017/7582398

Lynch, T., \& Soukup, G. J. (2016). Physical education, health and physical education, "physical literacy" and "health literacy": Global nomenclature confusion. Cogent Education, 3(1) https://doi.org/10.1080/2331186X.2016.1217820

Mastoras, S. M., Saklofske, D. H., Schwean, V. L., \& Climie, E. A. (2015). Social support in children with ADHD: An exploration of resilience. Journal of Attention Disorders, 22(8), 712-723. https://doi.org/10.1177/1087054715611491

Meng, Q., Zhu, C., \& Cao, C. (2018). Chinese international students' social connectedness, social and academic adaptation: The mediating role of global competence. Higher Education, 75(1), 131-147. https://doi.org/10.1007/s10734-017-0129-x

Michaels, S., \& O’Connor, C. (2015). Conceptualizing talk moves as tools: Professional development approaches for academically productive discussions. Socializing intelligence through academic talk and dialogue, 347-361. https://doi.org/10.3102/978-0-935302-43-1_27

Mirković, B., Brady, B., \& Silke, C. (2021). Associations between non-parental adult support and youths' individual and contextual characteristics. Child Care in Practice, 1-16. https://doi.org/10.1080/13575279.2020.1865875

94 Consortia Academia Publishing (A partner of Network of Professional Researchers and Educators) 
Influence of social support to student learning and development

Naslund, J. A., Aschbrenner, K. A., Marsch, L. A., \& Bartels, S. J. (2016). The future of mental health care: peer-to-peer support and social media. Epidemiology and Psychiatric Sciences, 25(2), 113-122. https://doi.org/10.1017/s2045796015001067

Nigg, C. R., \& Amato, K. (2014). The influence of health behaviors during childhood on adolescent health behaviors, health indicators, and academic outcomes among participants from Hawaii. International Journal of Behavioral Medicine, 22(4), 452-460. https://doi.org/10.1007/s12529-014-9440-4

Noble-Carr, D., Barker, J., McArthur, M., \& Woodman, E. (2014). Improving practice: The importance of connections in establishing positive identity and meaning in the lives of vulnerable young people. Children and Youth Services Review, 47, 389-396. https://doi.org/10.1016/j.childyouth.2014.10.017

Okoedion, E. G., Okolie, U. C., \& Udom, I. D. (2019). Perceived factors affecting students' academic performance in Nigerian Universities. Studi Sulla Formazione, 22(2), 409-422. https://doi.org/10.13128/ssf-10814

Owens, A. (2017). Racial residential segregation of school-age children and adults: The role of schooling as a segregating force. RSF: The Russell Sage Foundation Journal of the Social Sciences, 3(2), 63-80. https://doi.org/10.7758/RSF.2017.3.2.03

Peeters, M. C. W., Buunk, B. P., \& Schaufeli, W. B. (1995). Social interactions and feelings of inferiority. Journal of Applied Social Psychology, 25(12), 1073-1089. https://doi.org/10.1111/j.1559-1816.1995.tb00618.x

Pinchover, S., \& Attar-Schwartz, S. (2018). Is someone there for you? Social support of youth in educational residential care from family, peers and as of Social Work, 48(8), 2195-2214. https://doi.org/10.1093/bjsw/bcx164

Preyde, M., Tran, A., Parekh, S., \& Heintzman, J. (2018). The health and well-being of children and adolescents accessing in-patient Psychiatry: A brief report. Journal of the Canadian Academy of Child and Adolescent Psychiatry, 27(3), 191-196.

Rice, L., Barth, J. M., Guadagno, R. E., Smith, G. P. A., \& McCallum, D. M. (2013). The role of social support in students' perceived abilities and attitudes toward Math and Science. Journal of Youth and Adolescence, 42(7), 1028-1040. https://doi.org/10.1007/s10964-012-9801-8

Reyes, M. E. (2020). Relative importance of social support and social connectedness as protective factors of suicidal ideation among selected Filipino late adolescents.

Sadoughi, M., \& Hesampour, F. (2016). Relationship between social support and loneliness and academic adjustment among University Students. International Journal of Academic Research in Psychology, 3(2). https://doi.org/10.6007/ijarp/v3-i2/2455

Saleem, F. T., English, D., Busby, D. R., Lambert, S. F., Harrison, A., Stock, M. L., \& Gibbons, F. X. (2016). The impact of African American parents' racial discrimination experiences and perceived neighborhood cohesion on their racial socialization practices. Journal of Youth and Adolescence, 45(7), 1338-1349. https://doi.org/10.1007/s10964-016-0499-X

Sapungan, G. M., \& Sapungan, R. M. (2014). Parental involvement in child's education: Importance, barriers and benefits.

Sarı, İ., Çeliköz, N.,\& Süleyman, U. (2017). The effect of peer support on university level students' English Language Achievements. Journal of Education and Practice. 8.

Schonert-Reichl, K. A. (2007). Middle childhood inside and out: The psychological and social world of children ages 9 to 12. Burnaby, BC: United Way of the Lower Mainland.

Schonert-Reichl, K. A. (2011). Middle childhood inside and out: The psychological and social worlds of Canadian children ages 9-12, Full Report. Report for the United Way of the Lower Mainland. Vancouver: University of British Columbia.

Shek, D. T., Zhu, X., \& Ma, C. M. (2018). The influence of parental control and parent-child relational qualities on adolescent internet addiction: A 3-Year Longitudinal Study in Hong Kong. Frontiers in Psychology, 9. https://doi.org/10.3389/fpsyg.2018.00642

Shevtsova, O., Tan, Y. F., Merkley, C. M., Winocur, G., \& Wojtowicz, J. M. (2017). Early-age running enhances activity of adult-born dentate granule Neurons following learning in Rats. eNeuro, 4(4), ENEURO.0237-17.2017. https://doi.org/10.1523/ENEURO.0237-17.2017 
Shin, K. M., Cho, S. M., Shin, Y. M., \& Park, K. S. (2016). Effects of early childhood peer relationships on adolescent mental health: A 6- to 8-year follow-up study in South Korea. Psychiatry investigation, 13(4), 383-388. https://doi.org/10.4306/pi.2016.13.4.383

Shubert, J., Wray-Lake, L., Syvertsen, A. K., \& Metzger, A. (2019). The role of family civic context in character development across childhood and adolescence. Applied Developmental Science, 1-16. https://doi.org/10.1080/10888691.2019.1683452

Southwick, S. M., Sippel, L., Krystal, J., Charney, D., Mayes, L., \& Pietrzak, R. (2016). Why are some individuals more resilient than others: the role of social support. World psychiatry: official journal of the World Psychiatric Association (WPA), 15(1), 77-79. https://doi.org/10.1002/wps.20282

Sparks, S. D. (2018). Homework: "maternal homework assistance and children's task-persistent behavior in Elementary School". Education Week, 37(31).

Student Well-Being is the "Real Purpose" of K-16 Education: Dr. Henry G. Brzycki launches new series of articles on SEL, student success, and well-being outcomes through schooling (2019). PR Newswire. ProQuest. https://www.proquest.com/wire-feeds/student-well-being-is-real-purpose-k-16-education/doc view/2166978294/se-2?accountid=31259

Southwick, S. M., Sippel, L., Krystal, J., Charney, D., Mayes, L., \& Pietrzak, R. (2016). Why are some individuals more resilient than others: the role of social support. World psychiatry: Official Journal of the World Psychiatric Association (WPA), 15(1), 77-79. https://doi.org/10.1002/wps.20282

Sultan, S., Hussain, I., \& Fatima, S. (2020). Social connectedness, life contentment, and learning achievement of undergraduate University students-does the use of internet matter? Bulletin of Education and Research, 42(1), 111.

Taylor, Z. E., Conger, R. D., Robins, R. W., \& Widaman, K. F. (2015). Parenting practices and perceived social support: Longitudinal relations with the social competence of Mexican-origin Children. Journal of Latina/o psychology, 3(4), 193-208. https://doi.org/10.1037/lat0000038

Tellhed, U., Bäckström, M., \& Björklund, F. (2016). Will I fit in and do well? The importance of social belongingness and self-efficacy for explaining gender differences in interest in STEM and HEED majors. Sex Roles, 77(1), 86-96.

Tomacruz, S. (2018). A cry for help: Mental illness, suicide cases rising among youth. Rappler. https://www.rappler.com/newsbreak/in-depth/211671-suicide-cases-mental-health-illness-youth-rising-p hilippines

Thomas, A., Caldwell, CH., \& De Loney,EH. (2012). Black like me: The race socialization of African American boys by nonresident fathers In Sullivan JM, \& Esmail AM (Eds.), African American racial identity: A research exploration across disciplines (pp. 249-272). Lanham, MD: Lexington Books/Rowman \& Littlefield.

Van der Veen, C., De Mey, L., Van Kruistum, C., \& Van Oers, B. (2017). The effect of productive classroom talk and metacommunication on young children's oral communicative competence and subject matter knowledge: An intervention study in early childhood education. Learning and Instruction, 48, 14-22. https://doi.org/10.1016/j.learninstruc.2016.06.001

Vandell, D. L., Shernoff, D. J., Pierce, K. M., Bolt, D. M., Dadisman, K., \& Brown, B. B. (2005). Activities, engagement, and emotion in after-school programs (and elsewhere). New Directions for Youth Development, 2005(105), 121-129. https://doi.org/10.1002/yd.111

Vygotsky, L. S. (1978). Mind in society: The development of higher psychological processes. Massachusetts: Harvard University Press.

Wang, M. T., \& Holcombe, R. (2010). Adolescents' perceptions of school environment, engagement, and academic achievement in middle school. American educational research journal, 47(3), 633- 662.

Wang, L., Liang, L., Liu, Z., Yuan, K., Ju, J., \& Bian, Y. (2021). The Developmental Process of Peer Support Networks: The Role of Friendship. Frontiers in psychology, 12, 615148. https://doi.org/10.3389/fpsyg.2021.615148

Wittink, D., \& Bayer L. (1994). The measurement imperative. Marketing Research, 6(4), 14-23.

Wright, K. B., Rosenberg, J., Egbert, N., \& Ploeger, N. A., (2013). Communication competence, social support,

96 Consortia Academia Publishing (A partner of Network of Professional Researchers and Educators) 
and depression among college students: a model of Facebook and face-to-face support network influence'. Journal of Health Communication, 18(1), 41-57. https://doi.org/10.1080/10810730.2012.688250

Yan, N., Zhou, N., \& Ansari, A. (2016). Maternal depression and children's cognitive and socio-emotional development at first grade: The moderating role of classroom emotional climate. Journal of Child and Family Studies, 25(4), 1247-1256. https://doi.org/10.1007/s10826-015-0301-9

Yang, Y. (2017). The impact of positive school experiences and school on depressive symptoms in Chinese Children: A multilevel investigation. International Journal of Child, Youth \& Family Studies, 8(2), 37-58. https://doi.org/10.18357/ijcyfs82201717758

Zandvliet, D. B., Stanton, A., \& Dhaliwal, R. (2019). Design and validation of a tool to measure associations between the learning environment and student well-being: The Healthy Environments and Learning Practices Survey. Innovative Higher Education, 44(4), 283-297. https://doi.org/10.1007/s10755-019-9462-6

Zinke, C. M. (2019). Exploring how community college transfer students experience connection in a Commuter University (Order No. 27549101). ProQuest Central. (2352129644). 
Baria, K., \& Gomez, D.

98 Consortia Academia Publishing (A partner of Network of Professional Researchers and Educators) 